\title{
ANALISIS KINERJA ROUTING PROTOKOL RIPNG DENGAN OSPFV3 PADA JARINGAN IPV6 TUNNELING
}

\author{
Harni Kusniyati ${ }^{1}$, Raka Yusuf ${ }^{2}$, Bayu Candra Wiraka ${ }^{3}$ \\ Jurusan Informatika, Fakultas IImu Komputer, Universitas Mercu Buana \\ Jl. Raya Meruya Selatan, Kembangan, Jakarta 11650 \\ E-mail : harni.kusniyati@mercubuana.ac.id ${ }^{1}$, raka@mercubuana.ac.id ${ }^{2}$, bayucandra03@gmail.com ${ }^{3}$
}

\begin{abstract}
The main objective of the development ipv6 is to meet need of ip addresses for a long term and improving the existing weaknesses in ipv4. But the transitional of the protokol version 4 to protokol version 6 cant be done by casually because due to the many infrastructure of the ipv4 network have been installed. For it is needed method to integrate ipv4 with ipv6 and one of the method is to use tunneling. The presence of tunneling network also needed routing protokol that support ipv6 protokol such as ripng and ospfv3 in ipv6 tunneling network. This paper is arranged to determine the performance of ripng dan ospfv3 routing protokols by analyzing the patch selection of data transmission, routing update analysis, speed time convergent analysis, analyzing by sending tcp data packet and sniffing analysis of data packet in tunneling network. The method used is literature study, computer simulation, and implementation on the test-bed. Data analysis showed that performance of ospfv3 is better than ripng because the speed of convergent time is faster. Ospfv3 need an average time as musch as 19 seconds but ripng need 178 seconds.on the test results of network throughput for tcp windows size that have 2, 4, 5, 6 kbyte capacity it take an average 121, 58 mbit/sec for ospfv3 and 117, $44 \mathrm{mbit} / \mathrm{sec}$ for ripng. For the overall performance of ripng and ospfv3 are not much different from its predecessor routing protokol in ipv4 network, it just for ripng and ospfv3 have support for 128-bit ipv6 addressing.
\end{abstract}

Keyword: RIPNG, OSPFV3, IPV6, TUNNELING

\section{ABSTRAK}

Tujuan dikembangkanya ipv6 adalah untuk memenuhi kebutuhan alamat ip untuk jangka panjang sekaligus menyempurnakan berbagai kelemahan ipv4. Namun peralihan penggunaan protokol ip versi 4 ke versi 6 tidak bisa serentak begitu saja dilakukan karena sudah banyaknya infrastructure jaringan ipv4 yang sudah terpasang. Untuk itu dibutuhkan suatu metode untuk memadukan ipv4 dengan ipv6 salah satunya dengan menggunakan tunneling. Dengan hadirnya jaringan tunneling dibutuhkan routing protokol yang juga mendukung protokol ipv6 diantaranya ripng dan ospfv3. Skripsi ini disusun untuk mengetahui kinerja routing protokol ripng dan ospfv3 pada jaringan tunneling ipv6. Pengujian dilakukan dengan analisa pemilihan jalur pengiriman data, analisa update routing, analisa kecepatan waktu konvergen, analisa pengiriman paket data tcp dan analisa sniffing paket data pada jaringan tunneling. Metode yang digunakan adalah studi literature, simulasi pada komputer dan implementasi pada jaringan test-bed. Analisa menunjukan secara kinerja ospfv3 lebih baik dibandingkan ripng dikarenakan kecepatan waktu konvergen yang lebih cepat. Pada ospfv3 dibutuhkan waktu rata-rata sebesar 19 detik sedangkan ripng sebesar 178 detik. Pada hasil pengujian throughput jaringan dengan windows size paket tcp berukuran 2, 4, 5, 6 kbyte didapatkan nilai rata-rata 121, $58 \mathrm{mbit} / \mathrm{sec}$ untuk ospfv3 dan 117, $44 \mathrm{mbit} / \mathrm{sec}$ untuk ripng. Secara umum kinerja ripng dan ospfv3 juga tidak jauh berbeda dengan pendahulunya pada jaringan ipv4 hanya saja pada ripng dan ospfv3 mendukung pengelamatan 128-bit ipv6.

Kata Kunci: RIPNG, OSPFV3, IPV6, TUNNELING

\section{PENDAHULUAN}

Dengan semakin berkembangnya pengguna internet kebutuhan akan IP (Internet Protokol) juga semakin bertambah. Namun pertambahan penggunaan IP ini tidak dapat diimbangi dengan jumlah IPv4 yang ada, oleh karena itu IETF (Internet Engineering Task Force) menetapkan standar pengelamatan baru yaitu IPv6, diharapkan dengan IPv6 ini dapat memenuhi kebutuhan alamat IP dan menyempurnakan berbagai kelemahan IPv4.

Namun karena sudah banyaknya infrastruktur jaringan IPv4 dengan skala besar, maka kita tidak dapat langsung mengganti seluruh jaringan IPV4 yang sudah ada dengan IPv6, selain membutuhkan waktu juga banyak pertimbangan yang harus dipikirkan untuk memigrasikan seluruh jaringan. Maka dari itu salah satu alternative yang dapat kita lakukan adalah dengan mengintegrasikan jaringan IPv4 yang sudah dengan jaringan IPv6 yang baru dan salah satu metodenya adalah dengan menggunakan tunneling IPv6.

Dengan hadirnya jaringan integrasi IPv6 dan IPv4 dibutuhkan suatu routing protokol yang dapat mengatur jalanya pengiriman data, dan salah satu jenis routing protokol tersebut adalah RIPng dan OSPFv3. Setiap routing protokol memiliki karakteristik yang berbeda dalam kinerjanya 
mengatur suatu jaringan dan memiliki kelemahan dan kelebihan masing-masing.

Oleh karena itu pada skripsi kali ini akan dibahas dua jenis routing protokol yang sering digunakan pada jaringan Tunneling IPv6 yaitu RIPng dan OSPFv3, pembahasan akan dilakukan dengan menganalisa kinerja dan pengujian kedua routing protokol ini sehingga diharapakan setelah dilakukan analisa dapat ditentukan bagaimana kinerja suatu routing protokol pada jaringan tunneling IPv6.

\section{LANDASAN TEORI}

\section{$2.1 \quad$ IPV6}

IPv6 dikembangkan oleh IETF untuk dapat memenuhi kebutuhan IP yang diperlukan, selain itu IPv6 juga dikembangkan untuk mengatasi atau menyempurnakan kekurangan-kekurangan dari teknologi pendahulunya, yaitu IPv4. Kelebihan utama dari IPv6 adalah pengalamatannya yang luas, yaitu 128bit. Dengan demikian ada 2128 atau sekitar 3, 4 × 1038 alamat IPv6 yang berlimpah tersedia, sehingga dapat memenuhi kebutuhan IP saat ini maupun di masa mendatang. IPv6 ini dapat mengatasi masalah pada NAT (Network Address Translation) yang mengurangi atau menghalangi penggunaan dari aplikasi realtime yang membutuhkan hubungan dua arah. Pada IPv6 mendukung hirarki pengalamatan dan jumlah pengalamatan node yang lebih banyak, sehingga konfigurasi alamat lebih sederhana. Kelebihan dari IPv6 yang lain ialah kapabilitas untuk QOS (Quality Of Service), autentifikasi, dan privasi. Untuk QOS dimungkinkan untuk pemberian label pada paketpaket pada aliran trafik tertentu yang membutuhkan penanganan khusus, untuk autentifikasi dan privasi IPv6 mendukung autentifikasi, integritas data, dan kerahasiaan data.

\subsubsection{IPV6 Header}

Pada IPv6 digunakan header paket yang sederhana, dan dengan header yang sederhana paket dapat diproses secara lebih efisien. Header pada IPv6 merupakan penyederhanaan dari header IPv4 dengan menghilangkan bagian yang tidak dipergunakan atau jarang digunakan dan menambahkan bagian yang menyediakan dukungan yang lebih baik untuk keperluan mendatang.

Berikut penjelasan dari format header pada IPv6 :

- Version $\rightarrow$ Versi IP, enam untuk IPv6 (4-bit).

- $\quad$ Traffic Class $\rightarrow$ Klasifikasi trafik, field ini

- menentukan prioritas trafik atau paket dan digunakan untuk QOS (quality of service) (8bit).

- $\quad$ Flow Label $\rightarrow$ Label aliran dari trafik (20-bit).

- Payload Length $\rightarrow$ Field ini merupakan panjang dari paket data (16-bit).

- $\quad$ Next Header $\rightarrow$ Identifikasi tipe header setelah header IPv6 (8-bit).

- Hop Limit $\rightarrow$ Nilai akan dikurangi satu, jika melewati sebuah router (node)
- $\quad$ Source/ Destination Address $\rightarrow$ Alamat dari sumber dan tujuan.

- Extension Header $\rightarrow$ Sebagai informasi tambahan,

- $\quad$ yang ditempatkan diantara header IPv6 dengan

- $\quad$ header yang lebih tinggi diatasnya

\subsection{Routing Protokol}

Routing adalah suatu protokol yang digunakan untuk mendapatkan rute atau petunjuk dari satu jaringan ke jaringan yang lain, routing merupakan proses dimana suatu router akan memilih jalur atau rute untuk mengirimkan atau meneruskan suatu paket ke jaringan yang dituju. Router menggunakan IP address tujuan untuk mengirimkan paket, dan agar router mengetahui rute mana yang harus digunakan untuk meneruskan paket ke alamat tujuan, router harus belajar atau bertukar informasi sesama router yang saling terhubung untuk mengetahui jalur atau rute yang terbaik. Routing protokol digunakan untuk memfasilitasi pertukaran informasi routing antar router. Dengan routing protokol, router dapat berbagi informasi routing table, yaitu informasi mengenai jaringan lain yang saling terhubung. Ada beberapa routing protokol yang mendukung IPv6, yaitu RIPng, OSPFv3 EIGRP for IPv6 (Cisco properiarity), IS-IS for IPv6, BGP IPv6, dan lainnya. Masingmasing dibuat berdasarkan routing protokol sebelumnya yang mendukung IPv4 namun disesuaikan dengan lingkup IPv6 dan memiliki beberapa kelebihan dan pembaharuan serta cara konfigurasi yang berbeda pada router.

\subsubsection{OSPFV3}

Open Shortest Path First (OSPF) adalah routing protokol kelas link-state yang dikembangkan untuk memperbaiki kinerja dari routing protokol RIP. OSPF adalah routing protokol yang menggunakan konsep area. Kelebihan dari OSPF dibandingkan dengan RIP adalah kecepatan dalam melakukan konvergensi dan lebih luasnya jaringan yang bisa dijangkau. Pada dasarnya OSPFv3 menggunakan jenis paket yang sama pada OSPFv2. Perbedaan yang paling jelas ialah OSPFv3 mendukung pengalamatan 128-bit. OSPFv2 menggunakan alamat 224.0.0.5 dan 224.0.0.6, OSPFv3 menggunakan alamat multicast IPv6 yaitu FF02::5 dan alamat FF02::6 untuk router DR (designated routers) dan BDR (Backup DRs). OSPFv3 menggunakan alamat link-localnya untuk malakukan advertisements bukan alamat globalnya. Paket header OSPFv3 adalah sebesar 16-byte, berbeda dengan OSPFv2 sebesar 24-byte. Paket header OSPFv3. Pada IPv6 kemampuan dalam autentikasi dan enkripsi menggunakan header extension. Pada OSPF terdapat beberapa paket LSP (Link-State Packet), masing-masing paket dibutuhkan dalam proses routing pada OSPF. Berikut paketpaket LSP pada OSPF :

Hello - Paket Hello digunakan untuk memulai dan menjaga keterhubungan informasi dengan router OSPF yang lain. 
DBD (Paket Database Description) - DBD untuk memeriksa dan melakukan sinkronisasi database antar router.

LSR ( Link-State Request) - LSR digunakan untuk menarik informasi dari router lain.

LSU ( Link-State Update) - Paket ini digunakan untuk menjawab LSR

LSAck (Link-State Acknowledgment) - LSAck digunakan untuk mengkonfirmasi paket LSU yang diterima oleh router.

Masing-masing router OSPF menjaga database LSA yang diterima dari router lain. Ketika LSA dari semua router telah diterima maka router akan membangun sebuah local link-state database. OSPF menggunakan algoritma Dijkstra's shortest path first (SPF) untuk membangun sebuah SPF tree. SPF tree ini yang kemudian digunakan untuk membangun sebuah routing table dengan jalur terbaik guna mencapai jaringan yang lain. Berikut merupakan proses terjadinya konvergensi pada link-state routing protokols:

Masing-masing router mempelajari koneksinya yang terhubung ke jaringan secara langsung.

Tiap router bertanggung jawab untuk "Hello" ke router tetangga yang terhubung langsung.

Router membangun Link-State Packet (LSP) yang berisi mengenai informasi link yang terhubung langsung.

Masing-masing router akan mengirimkan LSP kesemua tetangganya, yang kemudian disimpan pada database.

Tiap router menggunakan databasenya untuk membangun sebuah peta topologi lengkap dari jaringan dan gambaran jalur atau rute yang dapat digunakan untuk mencapai jaringan tujuan yang ingin dicapai.

Administrative distance (AD) digunakan untuk mengukur realibilitas informasi routing yang diterima oleh sebuah router dari router tetangganya. Nilai AD berkisar pada bilangan bulat antara 0 sampai 255 , dimana 0 menunjukkan kemampuan penerusan data yang tertinggi dan 255 menunjukan tidak ada data yang akan diteruskan melewati sebuah rute. Secara default OSPF memiliki AD bernilai 110.

Metric yang digunakan pada routing protokol OSPF dinamakan cost, semakin kecil nilai cost, maka akan dipilih menjadi interface untuk mengirimkan data. Pada RFC 2328 tidak dijelaskan mengenai nilai acuan untuk cost, RFC 2328 : "A cost is associated with the output side of each router interface. This cost is configurable by the system administrator. The lower the cost, the more likely the interface is to be used to forward data traffic.

Namun pada Cisco IOS akumulasi bandwith dari interface yang digunakan router untuk mencapai tujuan dijadikan sebagai acuan nilai cost. Pada setiap router nilai cost dari interfacenya dihitung dari 10 pangkat 8 dibagi dengan nilai bandwidthnya (bps). Pada terlihat perbandingan nilai cost yang dihitung dari besarnya bandwidth.

\subsubsection{RIPNG}

RIP merupakan routing protokol distancevector yang masuk pada kelas Interior Gateway Protokol yang dikembangkan oleh IETF. Routing protokol ini menggunakan algoritma Bellman-Ford dalam penentuan jalur routing. RIP digunakan pada jaringan dengan ukuran kecil, dimana untuk implementasi dan konfigurasinya yang sederhana dan mudah. RIPng menggunakan protokol UDP pada port 521 untuk melakukan transportasi baik dalam pengiriman atau penerimaan datagram. RIPng termasuk dalam routing protokol distance vector yang menggunakan hop count dalam menentukan rute ke tujuan. Pada dasarnya cara kerja dari RIPng sama dengan RIP, karena RIPng dibuat berdasarkan routing protokol RIP yang digunakan pada IPv4. Namun salah satu perbedaan yang mendasar ialah dukungan pada pengalamatan IPv6.

RIP menggunakan hop count dalam memperhitungan jarak ke alamat tujuan. Hop count sebuah router menuju jaringan yang terhubung langsung adalah bernilai 0 , hop count dari sebuah router yang terhubung langsung dengan sebuah router adalah bernilai 1. Pada Gambar 2.3 menunjukan gambar paket header pada routing protokol RIPng. Penjelasan paket RIPng

Command Type mengidentifikasi tipe pesan RIPng, jika satu menunjukan paket request jika 2 menunjukan paket respon RIP.

Version number menunjukan versi protokol RIP.

Must be zero pada filed haru bernilai 0 .

Route Table Entry berisi variable IPV6 Prefix, Route, Prefix len, dan Metric.

\section{Cara kerja routing protokol RIP :}

Setelah RIP di-enable router akan mengirimkan permintaan atau request ke router tetangga, dan menerima request atau respon balik dari router tetangga.

Ketika respon balik diterima, router akan menerima informasi yang dikirim dan akan melakukan update terhadap routing table lokal.

Setiap router dengan routing protokol RIP akan melakukan hal yang sama agar tetap memiliki informasi routing yang terbaru.

Kekurangan dari routing protokol ini adalah terbatasannya jumlah lompatan (hop) yang dapat dijangkau, dimana hop maksimal yang bisa dijangkau adalah 15 hop.

\section{PERANCANGAN JARINGAN DAN PENGUJIAN}

\subsection{Topologi Jaringan}

Topologi jaringan yang digunakan untuk pengujian routing protokol RIPng dan OSPFv3 Menggunakan bentuk topologi ring dengan 3 buah router dan 2 buah PC dimana pada topologi tersebut perangkat end to end menggunaka IPV6 dan akan melewati jaringan IPv4 untuk pengiriman data, Topologi ditunjukan pada Gambar . 


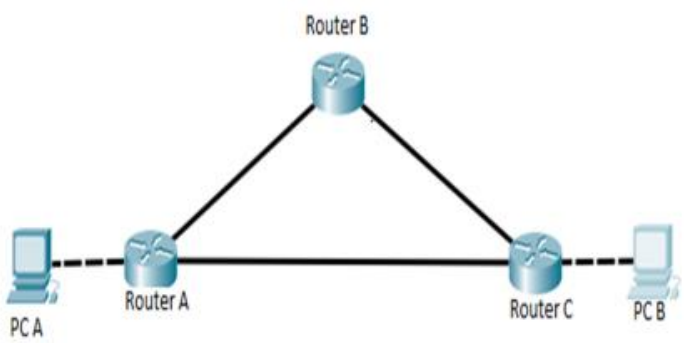

Gambar 3.1 Topologi Jaringan

Selain rute IPv4 untuk rute pengiriman datanya juga disediakan rute IPv6 sebagai alternative lain jalur pengirimann data, rute alternative akan digunakan untuk pengujian penentuan path dan penentuan waktu konvergensi jika salah satu rute terputus. Untuk alokasi penentuan IP dapat dilihat dari table berikut.

TABEL 3.1 TABEL ALOKASI IP

\begin{tabular}{|c|c|c|c|c|}
\hline No. & Nama perangkat & Interface & Alamat IP & Prefix \\
\hline \multirow{4}{*}{1} & \multirow{3}{*}{ ROUTER A } & Ether 2 & 10.10 .10 .1 & $/ 24$ \\
\cline { 3 - 5 } & & Ether 5 & $4000:: 1$ & $/ 64$ \\
\cline { 3 - 5 } & & Ether 6 & $6000:: 1$ & $/ 64$ \\
\cline { 3 - 5 } & & Tunnel 6to4 & $3000:: 1$ & $/ 64$ \\
\hline \multirow{2}{*}{2} & \multirow{2}{*}{ ROUTER B } & Ether 3 & $6000:: 2$ & $/ 64$ \\
\cline { 3 - 5 } & & Ether 4 & $7000:: 1$ & $/ 64$ \\
\hline \multirow{4}{*}{3} & \multirow{3}{*}{ ROUTER C } & Ether 1 & $2000:: 1$ & $/ 64$ \\
\hline & & Ether 2 & 10.10 .10 .2 & $/ 24$ \\
\hline & & Ether 4 & $7000:: 2$ & $/ 64$ \\
\cline { 3 - 5 } & & Tunnel 6to 4 & $3000:: 2$ & $/ 64$ \\
\hline 5 & PC A & LAN 1 & $4000:: 2$ & $/ 64$ \\
\hline 6 & PC B & LAN 1 & $2000:: 2$ & $/ 64$ \\
\hline
\end{tabular}

\subsection{Konfigurasi Jaringan}

\subsubsection{Perangkat Keras}

Pada perancangan jaringan guna mengimplementasikan topologi yang telah dirancang maka akan digunakan 2 jenis perangkat keras yaitu router dan PC, dimana terdapat 4 buah router Mikrotik dan 2 buah PC.

\subsubsection{Router Mikrotik RB100AHX2}

Mikrotik RouterOS adalah sistem operasi dan perangkat lunak yang dapat digunakan untuk menjadikan komputer manjadi router network yang handal, mencakup berbagai fitur yang dibuat untuk ip network dan jaringan wireless, cocok digunakan oleh ISP dan provider hotspot. Mikrotik router board adalah perangkat keras yang dikemas dengan OS Mikrotik RouterOS sehingga dapat berdiri sendiri layaknya sebuah PC yang sudah diinstal mikrotik RouterOS. Pada pengujian kinerja routing protokol nanti akan digunakan 4 buah router mikrotik RB100AHX2 sebagai media pengetesan.

\subsubsection{Konfigurasi Routing Protokol}

Untuk menghubungkan jaringan dengan beberapa router diperlukan suatu routing protokol untuk menentukan arah pengiriman datanya, konfigurasi routing protokol harus dilakukan pada setiap router, pada case dynamic routing protokol seperti RIPng dan OSPFv3 harus didaftarkan setiap interface route kedalam table routing protokol yang digunakan.Setelah dilakukan konfigurasi IP pada setiap interface maka penambahan routing dapat dilakukan.

Untuk konfigurasi Routing protokol RIPng dilakukan sebagai berikut :

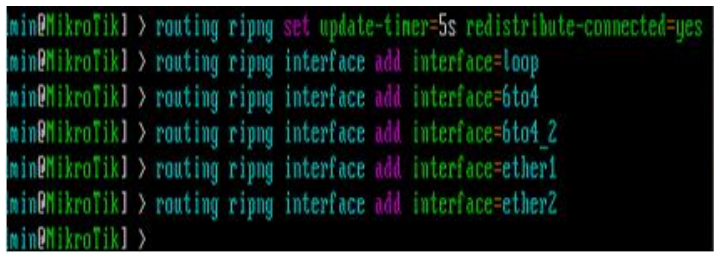

Gambar 3.2 Konfigurasi Routing RIPng

Langkah pertama dilakukan dengan mengenable kan feature RIPng mendaftarkan setiap interface ke protokol RIPng tersebut.Untuk konfigurasi Routing protokol OSPFv3 dapat dilakukan sebagai berikut :

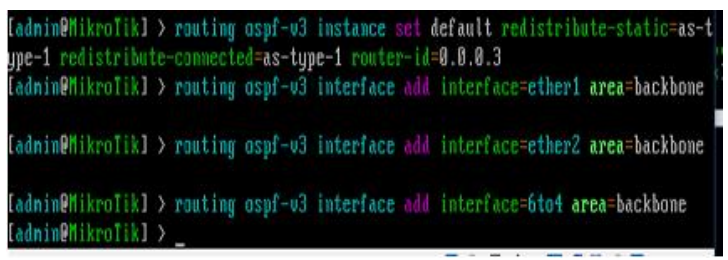

Gambar 3.3 Konfigurasi Routing OSPF-v3

Langkah hampir sama dengan RIPng, untuk OSPFv3 dilakuakn dengan mengenablekan feature OSPFv3 kemudian mendaftarkan setiap interface kerouting protokol OSPFv3 tersebut.

\subsubsection{Konfigurasi Tunnel IPV6}

Untuk melewatkan data IPv6 melewati jaringan IPv4 dalah satunya adalah dengan dilakukan tunneling IPv6 dan berikut konfigurasi pada router mikrotik.

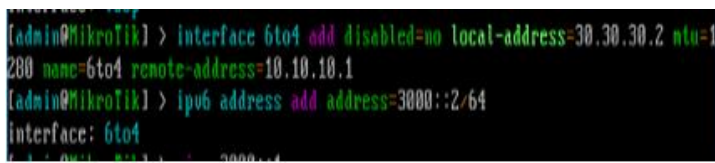

Gambar 3.4 Konfigurasi Tunnel IPv6

Untuk local address adalah IP interface router tersebut, untuk remote address adalah IP router tujuan tunnel. Untuk IP tunnel juga digunakan IPv6 addres.

\section{3 .Metode Pengujian}

3.3.1 Pengujian Pemilihan Jalur Pengiriman Data Pada setiap routing protokol memiliki routing table dimana pada setiap routing table tersebut berisi rute-rute atau jalur untuk mencapai jaringan lain, untuk mengecek routing table dapat dilakukan dengan mengetikan perintah "ipv6 route" pada router mikrotik. Pada pengujian pemilihan jalur pengiriman data akan dilakukan dengan melihat routing table awal pada saat jaringan selesai dirancang. Routing table dilihat menggunakan winbox seperti gambar berikut 


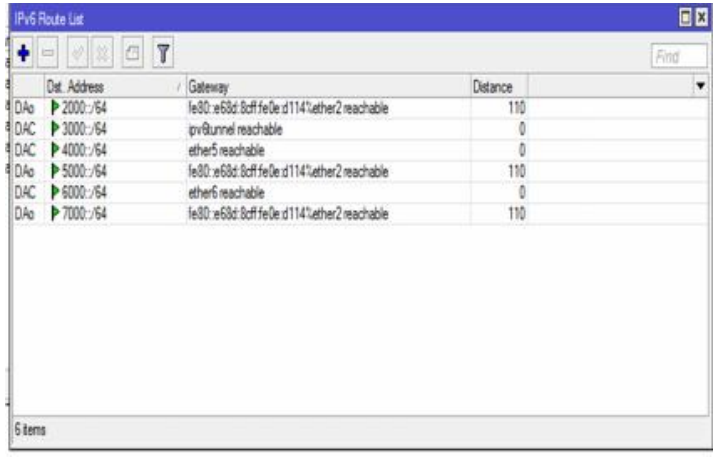

Gambar 3.5 Table Routing

Hasil routing table akandiuji dengan melakukan perintah "Trace route" atau "tracert" untuk mengecek rute pengiriman data melalui protokol ICMP (Internet Control Messaging Protokol) apakah sesuai dengan routing table atau tidak, pengujian trace dilakukan dari PC1 ke PC2 seperti pada gambar berikut :

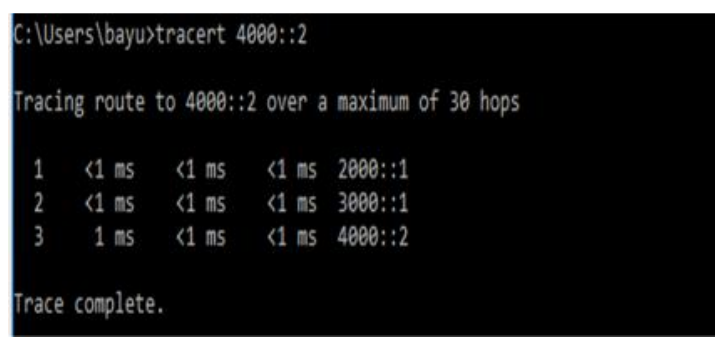

Gambar 3.6 Tracert PC B - PC A

\subsubsection{Pengujian Update Routing Table Dan Kecepetan Waktu Kovergensi}

Pada pengujian update routing dan kecepatan waktu konvergen akan dilakukan dengan memutuskan salah satu jalur utama pengiriman data, setelah jalur utama pengiriman data terputus akan dilihat perubahan routing table pada setiap routing protokol apak rute pengiriman datanya berubah atau tidak.

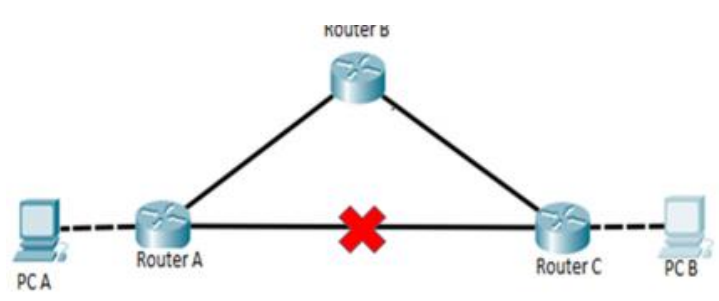

Gambar 3.7 Pemutusan jalur pengiriman data

Untuk pengecekan waktu konvergen akan dicek seberapa lama waktu yang dibutuhkan routing protokol unutk mengupdate routing tablenya sampai jaringan bisa terkoneksi kembali

\subsubsection{Pengujian Paket Data Pada Saat Melewati Tunneling Ipv6}

Pengujian kali ini juga dilakukan dengan capture paket data menggunakan wireshark pada salah satu jalur router yang melakukan tunneling.

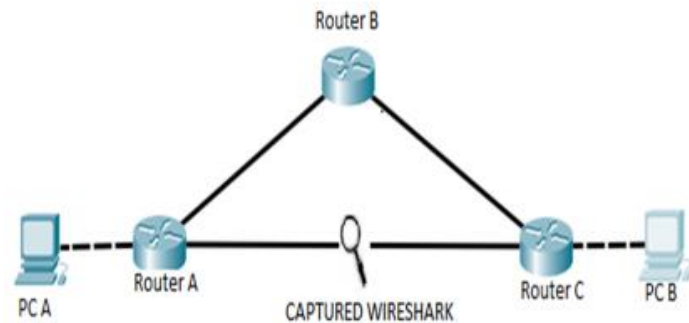

Gambar 3.8 Monitoring link wireshark

Pengujian dilakukan dengan mengirimkan paket data ICMP melewati tunneling kemudian akan diteliti karakteristik paket pada tunnel.

\subsubsection{Pengujian Performance Jaringan Dengan Pengiriman Paket TCP}

Untuk menguji performance jaringan akan disimulasikan mengirimkan paket data TCCP menggunakan IPERF dari PC1 sebagai client dan PC2 sebagai server, parameter yang akan dilihat adalah hasil throughput jaringanya. Untuk pengujian akan dilakukan dengan variasi besar data TCP yang berbeda yaitu $2000 \mathrm{~kb}-6000 \mathrm{~kb}$. Pengujian akan dilakukan bergaintian pertama dengan topologi RIPng kemudian dilanjutkan dengan OSPFv3. Contoh capture Iperf dengan throughput bandwith sebesar $65.8 \mathrm{Mbits} / \mathrm{sec}$.

\section{ANALISA}

\subsection{Analisa Pengujian Pemilihan Jalur} Pengiriman Data

Berdasarkan hasil pengujian jalur pengiriman pada routing protokol RIPng dan OSPFv3 dapat kita lihat bahwa kedua routing protokol ini memiliki rute yang sama pada pengiriman data dari PC A - PC B yaitu melewati jalur tunnel sebagai rute utama pengiriman datanya.

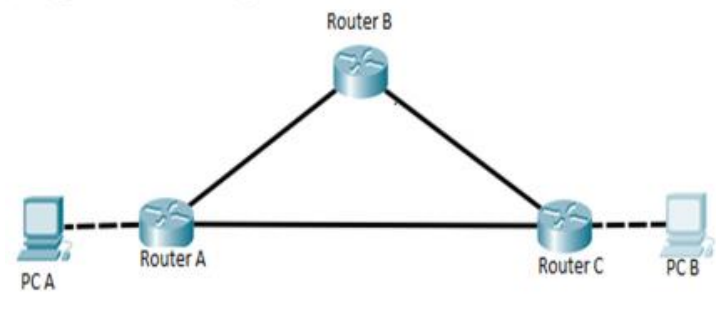

Gambar 4.1 Path pengiriman data

Jika kita lihat pada routing protokol RIPng penentuan jalur pengiriman datanya ditentukan berdasarkan perhitungan jumlah hop count (jumlah router yang dilewati) dimana jalur yang memiliki hop count terkecil akan menjadi jalur utama pengiriman datanya, pada kasus kali ini jika kita ingin mengirimkan data dari PC A - PC B maka terdapat dua pilihan jalur, yaitu dengan melewati jalur tunnel (2 hop) atau jalur lainya 3 (hop), berdasarkan perhitungan jumlah hop paling sedikit tentu RIPng akan memilih jalur tunnel sebagai jalur utamanya. 


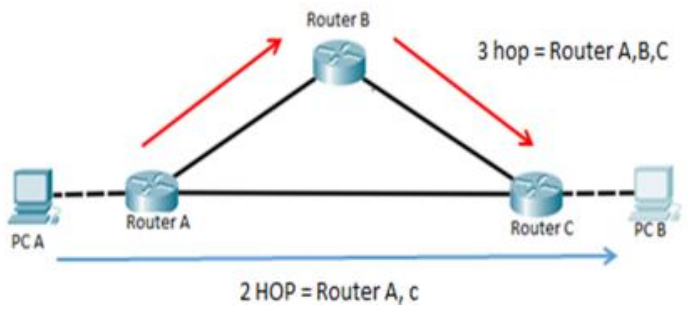

Gambar 4.2 Hop count RIPng

Sementara dalam OSPFv3 penentuan jalur ditentukan berdasarkan nilai cost pada setiap router jalur yang memiliki nilai cost terendah akan dipilih sebagai jalur utama pengiriman data.

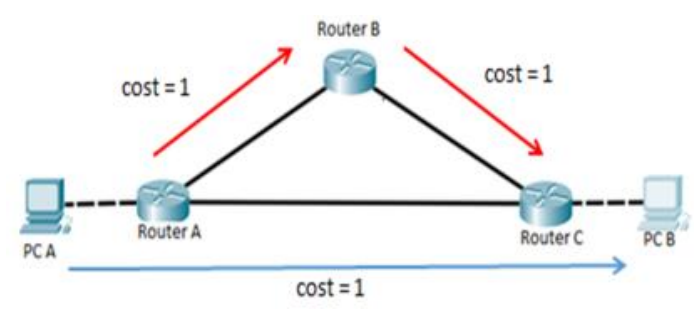

Gambar 4.3 Cost OSPFv3

Berdasarkan jumlah cost terkecil adalah melalui jalur tunnel router $\mathrm{A}$ - router $\mathrm{C}$.

\subsection{Analisa Pengujian Update Routing Dan Kecepatan Waktu Konvergensi}

Pada pengujian update routing dan kecepatan waktu konvergensi dilakukan dengan memutuskan salah satu jalur fisik pada rute utama pengiriman data, pada routing RIPng setelah dilakukan pemutusan jalur utama maka router dalam jangka waktu tertentu akan langsung mengupdate routing table mereka ke jalur alternative lain untuk pengiriman datanya menjadi seperti gambar berikut

\begin{tabular}{|c|c|c|c|}
\hline \multicolumn{3}{|l|}{ Foposte it } & \multirow{2}{*}{ Dix } \\
\hline t= & & & \\
\hline Ot Adtens & Gatenay & Datros & - \\
\hline Of $P 2000-84$ & 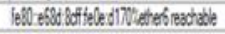 & 10 & \\
\hline DC P $3000-54$ & profmed unescrable & 255 & \\
\hline OAC P4000- 64 & therfeasctable & 0 & \\
\hline OKC PEOOOD-EA & therofresctable & 0 & \\
\hline of Prowo-64 & 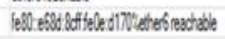 & 100 & \\
\hline
\end{tabular}

Gambar 4.4 RIPng update routing table

Dimana sebelumnya untuk rute pengiriman data menuju IP 2000::/64 (PC B) melewati ether 2, berpindah menjadi melewati ether 6 .

Begitu pula dengan OSPFv3 setelah dilakukan pemutusan jalur, OSPFv3 mengupdate routing table nya menjadi seperti berikut :

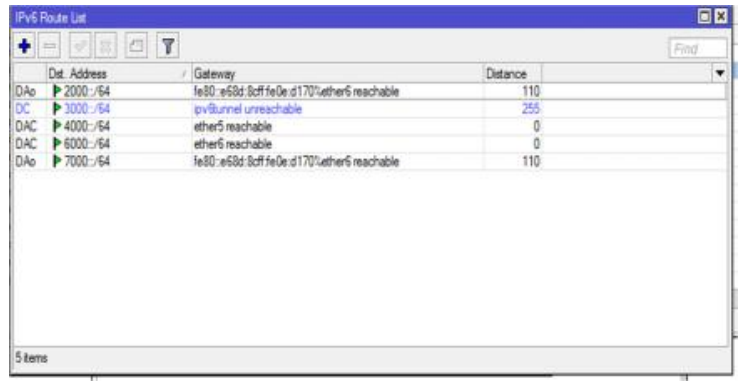

Gambar 4.5 OSPFv3 update routing table

Keadaan konvergen pada suatu jaringan dapat dicapai ketika setiap router telah siap mengirimkan data dan semua komponen jaringan dapat saling terkoneksi, untuk mengetest waktu konvergen dan kecepatan setiap routing protokol dalam mengupdate routing tablenya dapat dilakukan test pemutusan jalur kemudian dihitung sampai berapa lama waktu yang dibutuhkan setiap router untuk mengupdate routing tablenya. Pada routing protokol RIPng setelah dilakukan 5 kali percobaan. Sementara dalam OSPFv3 membutuh setelah dilakukan 5 kali percobaan.

Dari hasil pengujian waktu kovergensi protokol RIPng memiliki rata-rata waktu kovergensi sebanyak 178 detik sedangkan OSPFv3 memiliki rata-rata waktu kovergensi sebanyak 19 detik.

\subsection{Analisa Pengujian Performance Jaringan Dengan Pengiriman Paket Tcp}

Untuk pengujian performance jaringan dilakukan 5 kali percobaan dengan menggunakan beban yang berbeda pada setiap percobaanya. Pada routing protokol RIPng dilakukan pengiriman data TCP melalui IPERF dari PC A - PC B maka dihasilkan data throughput bandwith Rata-rata 117.44 Mbits/sec

Sementara untuk protokol OSPFv3 dihasilkan data throughput bandwith rata-rata 121.58 Mbits/sec

Dari hasil throughtput bandwith tersebut dapat kita lihat bahwa jumlah maksimal beban yang dapat ditampung pada suatu pengiriman data sangat berpengaruh pada jumlah bandwith yang kita dapat, semakin tinggi jumlah maksimal beban yang dapat dilewatkan maka semakin besar juga jumlah bandtwith yang kita terima.

\subsection{Analisa Paket Data Pada Saat Melewati Tunnel Ipv6}

Pada saat dilakukan pengujian ICMP dari PC A - PC B pada awalnya paket data berasal jaringan IPv6 namun pada saat melalui jaringan IPv4 (tunnel) ternyata bentuk paket masih berupa paket IPv6 yaitu ICMPv6 hanya saja pada header paket ditambahkan source dan destination IPv4 sebagai rute tujuannya, hal tersebut dapat kita lihat pada paket data ICMP yang tercapture pada saat melewati tunnel. 


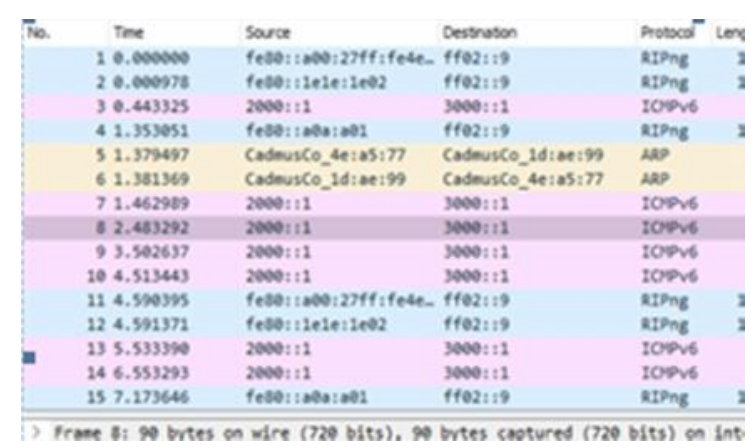

Gambar 4.6 Detail ICMP packet

\subsubsection{Analisa Paket Data Ripng Pada Jaringan Tunneling \\ Pada routing protokol RIPng informasi yang} dibawa pada saat keadaan jaringan normal adalah informasi routing pada setiap pathnya dimana pada paket data RIPng di sertakan rute detail beserta nilai metric rute tersebut.

Namun pada saat dilakukan pemutusan salah satu jalur fisik jaringan, sebagai contoh diputusnya jalur fisik ke arah IP 3000::/64 maka routing protokol RIPng akan memberikan update bahwa destination ke IP 3000::/64 tidak dapat dicapai dengan memeberikan nilai metric pada IP tersebut sebesar 16, dimana nilai maksimum hop/metric pada RIPng adalah 15 dan jika ada nilai metric diatas 15 maka jaringan tersebut dianggap terputus atau tidak dapat dijangkau.

\subsubsection{Analisa Paket Data Ospfv3 Pada Jaringan Tunneling}

Pada OSPFv3 jenis paket yang dikirimkan adalah hello paket dimana dalam paket tersebut terdapat informasi OSPF, frame 41 , ethernet dan IPv6 (source dan destination).

Masing-masing router mengirimkan hello paket pada setiap router neighbornya dimana pada setiap hello paket terdapat informasi ospf mengenai router mana yang menjadi designated routet, backup desighnated route dan active neghbornya. Pada paket OSPFv3 tidak dikirimkan informasi routing karena pada saat awal pembentukan neighbor setiap router sudah memetakan seluruh topologi jaringan didalam memorinya dan inilah yang menjadi kelebihan OSPFv3 yang mendukung kecepatanya dalam mengirimkan data.

Kemudian pada saat terjadi pemutusan salah satu jalur fisik maka secara otomatis routing protokol OSPFv3 akan mengirimkan 2 paket untuk menginformasikan adanya perubahan topologi dari satu router ke router lainya, nama paket tersebut adalah link state update dan link state acknowladge.

Pada kedua paket link state tersebut samasama berisi 2 jenis LSA type yaitu type 8201 (intra Area ) dan 8194 ( network LSA). Berbeda setelah jalur fisik yang tadi terputus dipasang kembali maka akan juga dikirimkan paket LS update dan LS aknowladge kembali namun dengan jumlah LSA yang lebih banyak yaitu dua type 8201 dan dua type 8194.

\section{PENUTUP}

\subsection{Kesimpulan}

1. Pada pengujian pemilihan jalur pengiriman data kedua routing protokol sama-sama menentukan jalur yang sama pada rute utama pengiriman datanya namun hal tersebut ditentukan berdasarkan metode yang berbeda-beda, jika RIPng menggunakan perhitungan hop count maka OSPFv3 menggunakan perhitungan cost. Dalam hal ini metode yang digunakan OSPFv3 tergolong lebih baik karena atribute yang digunakan untuk menggunakan cost nya lebih detail yaitu dengan membandingkan jumlah keseluruhan bandwith dimana total bandwith terbesar akan dijadikan rute utama pengiriman datanya.

2. Pada pengujian update routing dan kecepatan waktu konvergen OSPFv3 memliki rata-rata kecepatan update routing sebesar 19 detik, sedangkan RIP memiliki rata-rat kecepatan update routing sebesar 178 detik, dalam hal ini OSPv3 lebih diunggulkan karena memliki ratarata update yang lebih cepat

3. Pada pengujian pengiriman paket TCP OSPFv3 memiliki rata-rata throughput bandwith sebesar $171 \mathrm{Mbits} / \mathrm{Sec}$, sedangkan RIPng memiliki rata-rata throughput bandwith sebesar $159 \mathrm{Mbits} / \mathrm{Sec}$.

4. Pada pengujian analisa paket data dapat kita lihat bahwa pada routing protokol RIPng atribut paket termasuk seluruh informasi routing akan dikrimkan secara periodic sedangkan pada OSPFv3 hanya informasi router neighbor saja yang dikirimkan hal itu karena router OSPFv3 sudah memiliki gambaran seluruh topologi pada memorinya masing-masing, namun dengan menyimpan seluruh gambaran topologi dalam memori router akan menyebabkan kapasitas memori router menjadi banyak yang habis digunakan, inilah sebabnya hanya beberapa router yang memiliki kapasitas memori yang besar saja yang dapat menjalankan OSPFv3 secara optimal.

5. Berdasarkan hasil 4 pengujian diatas dapat kita lihat secara kinerja OSPFv3 memiliki kinerja yang lebih baik, baik dalam penentuan rute, hasil throughput pengujian pengiriman data yang lebih besar, serta update routing dan kecepatan konvergen yang lebih cepat.

\subsection{Saran}

1. Dikarenakan banyaknya keterbatasan dalam penggunaan IPvv4, sebagai perancangan jaringan kedepanya disarankan untuk menggunakan IPv6 sebagai protokol IPnya selain jumlah hostnya yang jauh lebih banyak, IPv6 memiliki banyak keunggulan seperti terhindar dari paket broadcast, keamanan yang lebih aman dan jenis paket headernya lebih sederhana.

2. Jika rancangan jaringan IPv6 kita buat memiliki lingkup yang sangat luas dan kompleks lebih disarankan untuk menggunakan routing protocol OSPFv3, selain 
memiliki kinerja yang lebih baik dibandingkan dengan RIPng, hal itu juga disebabkan karena RIPng memiliki batas maksimal hop yaitu hanya mencapai 16 hop pengiriman data jika melebihi jaringan akan dianggap unreacable.

3. Jika rancangan jaringan IPv6 yang kita buat hanya dalam lingkup kecil dan kapasitas router kita juga tidak terlalu besar lebih disarankan untuk menggunakan routing protocol RIPng karena tidak terlalu rumit dalam penggunaanya dan routing protocol RIPng juga tidak banyak memakan kapasitas penyimpanan router.

4. Untuk mengintegrasikan IPv6 dengan IPv4 terdapat 3 metode, sebaiknya disusaikan dengan kebutuhan jaringan kita. Jika hanya ingin melewatkan data antara jaringan IPv6 tetapi melewati jaringan IPv4 disarankan untuk menggunakan tunneling saja karena tidak perlu melakukan konfigurasi di semua router hanya pada 2 router yang melakukan tunneling, namun jika ingin mengirimkan data dari IPv6 ke IPv4 secara bersamaan dapat menggunakan metode dual stack atau dengan menggunakan metode NAT-PT.

\section{DAFTAR PUSTAKA}

Edi Yusuf, Dwi Aryantan dan Lita Lidyawati (2016). Perancangan dan analisis kinerja EIGRP pada jaringan IPv6(Tesis) Bandung : Institut Teknologi Nasional Bandung

Mifta Rahman (2012).OSPF (Open Shortest Path First).

https://belajarcomputernetwork.com/2012/06/0 5/ospf-open -shortest-path-first/

Muhamad Syafrudin (2010). Analisa unjuk kerja routing protokol RIPng dan OSPFV3 pada jaringan IPV6 (Tesis) Depok : Universitas Indonesia .

Pauline Rahmiati, Dwi Aryanta dan Taufiq Agung Priyadi (2014).perancangan dan analisis perbandingan implementasi OSPF pada jaringan IPv4 dan IPv6(Tesis) bandung :Institut Teknologi Nasional Bandung

Zekar, Simon. 2009. IPv6 over IPv4 tunnel with Mikrotik \& Cisco router. http://www.simon.zekar.com/2009/09/27/ipv6over-ipv4-tunnel-with-mikrotik-cisco-router/ 